\section{(2) OPEN ACCESS}

\title{
Effect of autologous adipose-derived mesenchymal stem cell therapy in the treatment of an osteochondral lesion of the ankle
}

\author{
Julien Freitag (D) , 1,2,3 James Wickham, ${ }^{2}$ Kiran Shah, ${ }^{3,4}$ Abi Tenen ${ }^{1,3,5}$
}

\begin{abstract}
${ }^{1}$ Melbourne Stem Cell Centre, Box Hill North, Victoria, Australia ${ }^{2}$ School of Biomedical Sciences, Charles Sturt University Orange Campus, Orange, New South Wales, Australia ${ }^{3}$ Magellan Stem Cells, Box Hill North, Victoria, Australia ${ }^{4}$ Swinburne University of Technology, Melbourne, Victoria, Australia

${ }^{5}$ School of Primary Health Care, Monash University, Notting Hill, Victoria, Australia
\end{abstract}

Correspondence to Professor Julien Freitag; julien.freitag@mscc.com.au

Accepted 17 June 2020

Check for updates

(c) BMJ Publishing Group Limited 2020. Re-use permitted under CC BY-NC. No commercial re-use. See rights and permissions. Published by BMJ.

To cite: Freitag J, Wickham J, Shah K, et al. BMJ Case Rep 2020;13:e234595. doi:10.1136/bcr-2020234595

\section{SUMMARY}

Osteochondral lesions (OCLs) of the talus are rare but can be associated with significant morbidity and may lead to the development of osteoarthritis. An improved understanding of the action of mesenchymal stem cells (MSCs) has seen renewed interest in their role in cartilage repair, with early preclinical and clinical research showing benefits in symptomatic and structural improvement. A 42-year-old man presented with an unstable $O C L$ of the talus and onset of early osteoarthritis with a history of multiple previous ankle arthroscopies for ankle impingement. The patient underwent arthroscopic removal of the $O C L$ in combination with adipose-derived MSC therapy. The patient reported progressive improvement as measured by the validated Foot and Ankle Disability Index. Repeat MRI with additional T2 mapping techniques showed successful regeneration of hyaline-like cartilage. This case is the first to show the successful use of MSC therapy in the management of an ankle OCL. Trial registration: Australian New Zealand Clinical Trials Registry ACTRN12617000638336.

\section{BACKGROUND}

Osteochondral lesions (OCLs) of the talus were first described and classified in 1959 by Berndt and Harty. ${ }^{1}$ These lesions can result in pain associated with weight bearing, loss of range of motion and mechanical symptoms of locking or instability resulting in significant mobility impairment. It is believed that OCLs are a precursor to early development of progressive osteoarthritis. ${ }^{23}$

Treatment strategies for OCLs of the ankle include surgical and non-surgical conservative management. Surgical treatments include surgical excision, excision combined with bone marrow stimulation techniques including curettage and microdrilling/microfracture, osteochondral autograft transfer system (OATS) and autologous chondrocyte implantation (ACI).

Non-surgical management with a period of immobilisation has been associated with successful improvement in pain and function between $29 \%$ and $69 \%$, though this typically is reserved for un-displaced and stable lesions. ${ }^{4-7}$ Direct excision of the OCL has been reported to have a success rate as low as $30 \% .^{8}$ Excision combined with curettage and/or other bone marrow stimulation techniques has a broad reported success rate of $46 \%$ to $100 \%$ though studies have questioned the long term viability of resultant fibrocartilage with early degeneration and recurrence of symptoms. ${ }^{8}$ The use of OATS has been associated with successful outcomes though it can be associated with considerable morbidity due to donor site pain. Several studies have also shown eventual loss of the graft chondral layer with degeneration of the surrounding native chondral surface. ${ }^{9}$ ACI techniques have been used with success but are technically difficult, require multiple surgeries and may be complicated by donor site morbidity and poor integration with surrounding cartilage. ${ }^{10}$ Recent research has assessed the use of an injectable bio-scaffold (BST-CarGel) in association with bone marrow stimulation techniques for isolated chondral lesions with reported improvements comparable to ACI at 12 months of follow-up. ${ }^{11}$

The ability of mesenchymal stem cells (MSCs) to differentiate along cell lines of mesodermal lineage (including osteoblasts and chondrocytes) has seen them being explored as an orthobiologic cellular therapy for tissue repair. ${ }^{12-14}$ However, despite their observed multi-potency, it is now more commonly accepted that their mechanism of action is primarily due to paracrine expression of cytokines, the release of secretomes/exosomes containing both cytokines and messenger RNA for direct horizontal translational upregulation of reparative cellular processes and by direct cell to cell interaction. ${ }^{15}$

Adult MSCs are found within various tissue types throughout the body. While bone marrow has commonly been used as a source of MSCs, it has surprisingly a relative paucity of MSCs with the MSC population comprising only $0.001 \%$ to $0.02 \%$ of the mono-nucleated cells isolated from bone marrow aspirate. ${ }^{16}{ }^{17}$ In comparison, human adipose tissue-obtained from a minimally invasive liposuction technique-yields MSC numbers of 1\% to $10 \%$ of the nucleated cell population. ${ }^{18}$ Importantly, previous research has shown adipose-derived MSCs (ADMSCs) to have an observed chondrogenic potential similar to bone marrow-derived MSCs. ${ }^{19} 20$

There is a growing body of pre-clinical and clinical research supporting the use of MSC therapy in the treatment of osteochondral defects/lesions. Wakitani and colleagues successfully used MSCimpregnated biological scaffolds in a limited clinical trial with successful repair of isolated chondral defects. $^{21}$ The use of injectable MSCs following 
bone marrow stimulation techniques including microdrilling has also resulted in significant regeneration of hyaline-like cartilage with Type II collagen confirmed on histopathology. ${ }^{22}$ We have shown in past publications the benefit of intra-articular injections of autologous ADMSCs in the treatment of an osteochondral defect of the knee and also of a focal post-traumatic chondral lesion of the patella. ${ }^{23}{ }^{24}$ Most recently, we have published a randomised controlled trial showing reproducible and significant pain reduction, functional improvement and disease progression modification following the use of ADMSC in the treatment of moderate (Kellgren-Lawrence Grade II-III) knee osteoarthritis. ${ }^{25}$

Despite the growing research on the role of MSC therapy in osteoarthritis and cartilage repair, there has been a paucity of research on joints other than the knee. Due to differing biomechanics, it cannot be presumed that results in other joints will be the same as that seen in treatment of the knee. The aim of this case study was to assess the efficacy of autologous ADMSC therapy in combination with excision and curettage of a focal OCL of the ankle. This case study is a part of a broader ethics approved and registered case series on the effect of MSC therapy in arthritis (Australian New Zealand Clinical Trials Registry - ACTRN12617000638336).

\section{CASE PRESENTATION}

A 42-year-old male presented with a painful right ankle. He had a history of previous repeat ankle surgical interventions. The patient was unable to comfortably walk prolonged distances and had been unable to return to his past chosen recreational sporting pursuits including running and basketball. The patient was otherwise well with no other past medical history.

The patient noted a history of initial ankle arthroscopy 13 years prior for symptoms of anterior impingement and ankle pain with removal of an anterior talar spur/prominence and chondroplasty/curettage to an area of unstable cartilage over the lateral talar dome. Due to recurrence of symptoms 4 years later, he underwent a formal talar osteotomy with unfortunately poor recovery and development of chronic pain and debility. Repeat imaging showed the presence/development of a repeat lateral talar dome chondral lesion for which he underwent arthroscopic curettage/osteoplasty and further to this a later periosteal graft procedure. Most recently, the patient had undergone a further arthroscopy with chondroplasty performed at the site of the previous periosteal graft.

Despite regular use of simple analgesics (paracetamol and non-steroidal anti-inflammatories), activity modification and physiotherapy, the patient failed to improve. Routine radiological assessment with X-ray showed early talo-cural joint osteoarthritis and an appearance of a lateral talar dome OCL (figure 1). Subsequent MRI confirmed an unstable OCL at the site of the previous periosteal graft with active bone marrow oedema deep to the sclerotic line of the OCL.

He was referred by his treating orthopaedic surgeon for consideration of ADMSC therapy in combination with arthroscopic excision and curettage.

The current level of evidence of MSC therapy was thoroughly discussed with the patient and he received formal written information regarding the use of and relative risks that may be associated with MSC therapy. Alternatives including excision and curettage in isolation, additional bone marrow stimulation methods and graft techniques including OATS and ACI were discussed. Prior to commencement of treatment, the patient completed formal written consent.

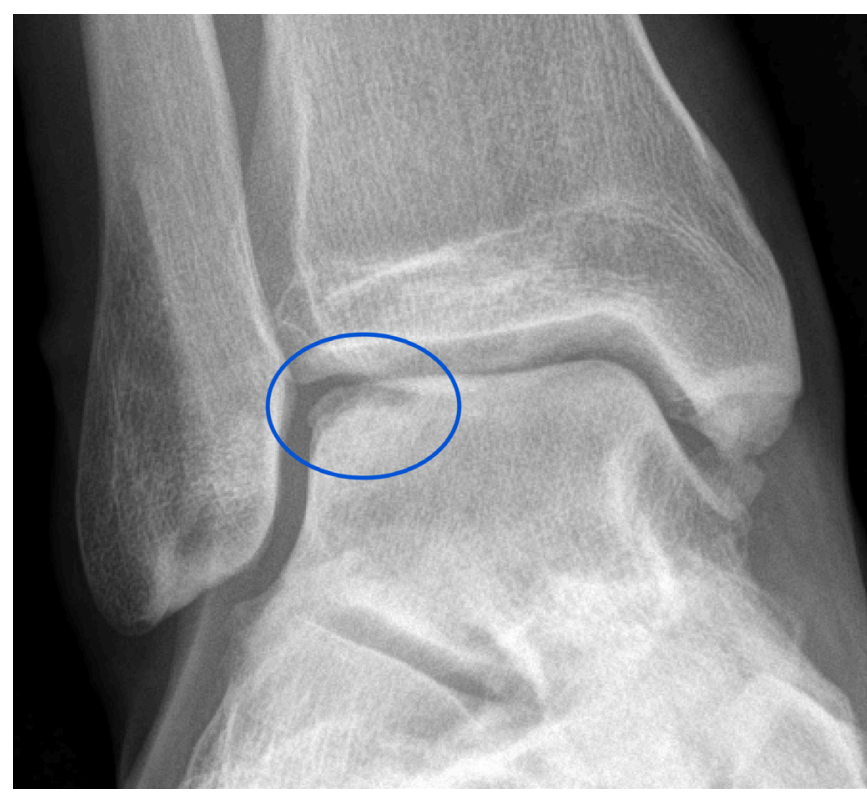

Figure 1 Pre-treatment X-ray showing evidence of an osteochondral lesion (blue circle).

\section{INVESTIGATIONS}

Routine radiological X-ray assessment showed evidence of osteoarthritis with mild early narrowing of the lateral talocrural joint space and evidence of an OCL (figure 1). MRI of the right ankle prior to arthroscopy confirmed a lateral talar dome OCL (figure 2). Repeat MRIs were performed at 3, 8, 12 and 24 months post commencement of ADMSC therapy (figure 2). Sequential quantitative MRI T2 mapping was performed to determine cartilage quality (figure 3 ).

\section{TREATMENT}

\section{Arthroscopic excision of OCL with curettage}

Under general anaesthetic and lower limb tourniquet control, the patient underwent right ankle arthroscopic examination. The area of the OCL was probed confirming instability of the OCL fragment. The fragment was excised using an arthroscopic grasper with an arthroscopic shaver used to debride the lesion to stable margins. Curettage was performed using an arthroscopic burr with removal of the sclerotic base of the OCL, exposing bleeding subchondral bone.

\section{Autologous ADMSC preparation}

\section{Harvest procedure}

The patient underwent a limited abdominal liposuction. This procedure has been formally described in past publications. ${ }^{23-26} \mathrm{In}$ summary, approximately $200 \mathrm{~mL}$ of tumescent fluid (comprising of $30 \mathrm{~mL}$ of $2 \%$ lignocaine, $1 \mathrm{~mL}$ of $1: 1000$ epinephrine, and $1 \mathrm{~mL}$ of $8.4 \%$ bicarbonate suspended in normal saline to a total volume of $1000 \mathrm{~mL}$ ) was infiltrated throughout the area of abdominal fat via two lateral abdominal incisions. Using a handheld manual suction technique (a $3 \mathrm{~mm}$ lipoaspirate cannula connected to a $20 \mathrm{~mL}$ syringe), $25 \mathrm{~mL}$ of lipoaspirate was collected. The lipoaspirate was then transferred directly to a clean room laboratory on site (Magellan Stem Cells, Melbourne, Australia).

\section{Isolation and expansion of MSCs}

The process of isolation and expansion has been previously described. $^{25} 27$ The isolation and expansion of ADMSCs was performed within a clean room laboratory with equivalent of 


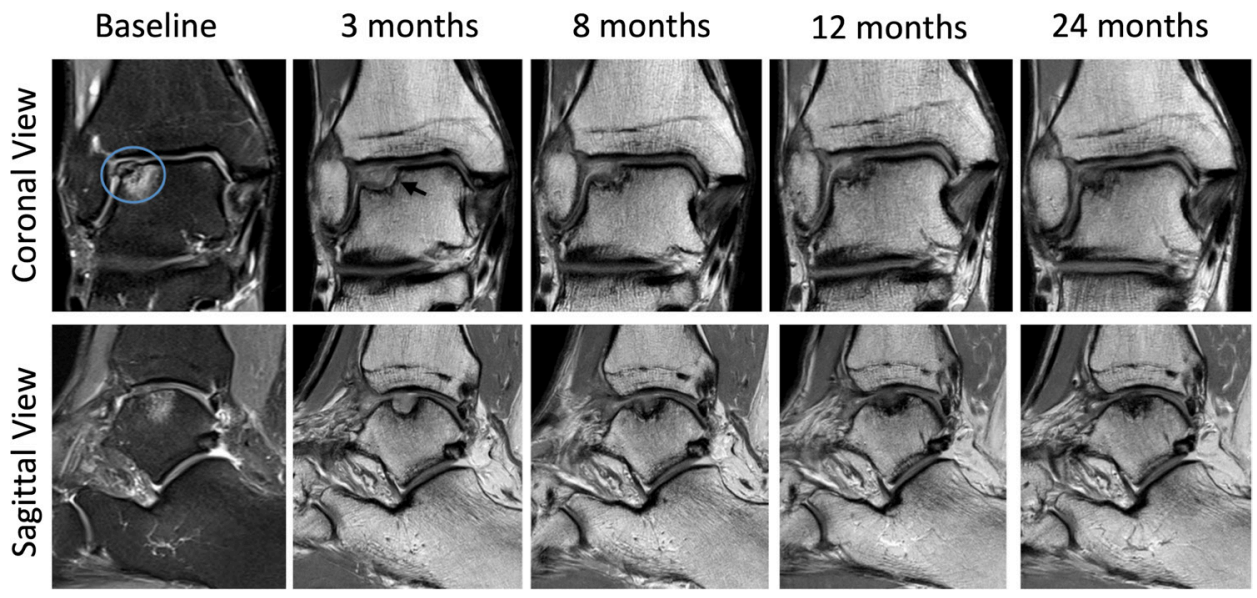

Figure 2 Sequential coronal and sagittal MRI images from baseline to 24 months showing progressive articular cartilage regeneration. Baseline PD fat-saturated MRI of the ankle confirmed an OCL. The area of bony oedema deep to the OCL border indicates instability (blue circle). PD coronal and sagittal images at 3, 8, 12 and 24 months of follow-up. The coronal view at 3 months indicates an area of lucency beneath the area of cartilage regeneration (black arrow). This resolves with subsequent imaging. $\mathrm{OCL}$, osteochondral lesion; $\mathrm{PD}$, proton density.

$>$ ISO 5 air quality and additionally within Class II biological safety cabinets.

Isolated ADMSCs were suspended in clinical grade MSC cryoprotectant media and cryopreserved using a validated control rate freezing method. ${ }^{252829}$

\section{Characterisation and sterility testing}

Flow cytometry fluorescence-activated cell sorting (FACS) analysis assessed for the presence of MSC surface markers as per previous criteria established by the International Society of Cellular Therapy (table 1$).^{30}$

Sterility testing was performed independently for microbial growth/contamination at completion of isolation and expansion.

\section{ADMSC carrier media preparation}

At the time of injection, ADMSCs were suspended in an autologous carrier media-autologous conditioned serum (ACS). A total of $27 \mathrm{~mL}$ of whole blood was withdrawn via venepuncture and collected in $3 \times 9 \mathrm{~mL}$ sterile S-Monovette clotting activator tubes (Starstedt, Numbrecht, Germany). Following collection, the tubes were incubated at $38^{\circ} \mathrm{C}$ for 24 hours and then centrifuged at $1000 \mathrm{rpm}$ for $5 \mathrm{~min}$ with separation of the plasma and cellular components. The plasma layer was removed and filtered through a 0.2-micron syringe filter (PALL, New York, USA) resulting in an acellular sample of ACS.

\section{ADMSC treatment protocol and injection method}

ADMSCs were taken out of cryopreservation and thawed in a sterile water bath. The cyroprotectant media was removed by

repeat centrifugation and washing of the cell pellet in chilled phosphate-buffered saline. The resultant ADMSC cell pellet was re-suspended in ACS to a total of $2 \mathrm{~mL}$. A Muse Cell Analyser (Merck, Millipore, USA) was used to confirm cell number and viability.

It was planned that the patient would receive approximately 20 million ADMSCs at baseline and again at 6 months. After review at 12 months and due to observed incomplete chondral regeneration, the patient underwent a third and final injection of approximately 50 million ADMSCs (see table 2 ).

All injections were performed using an aseptic technique and under direct visualisation with the use of ultrasound (US). Local anaesthetic ( $1 \mathrm{ml} 2 \%$ lidocaine) was infiltrated superficial to the joint capsule of the talo-crural joint line using an anterolateral approach. The ADMSCs re-suspended in ACS to a total of 2 $\mathrm{mL}$ were subsequently injected under US guidance into the intraarticular space using the same approach.

\section{Outcome measures/analysis}

Functional outcome was assessed throughout the follow-up period using the following validated clinical outcome questionnaires at $0,1,3,6,12$ and 24 months.

1. Foot and Ankle Disability Index (FADI): FADI consists of 26 items including four pain-related items and 22 activityrelated items and is a validated measure of foot and ankle function. ${ }^{3132}$ Each item is scored on a 5-point Likert scale with activity items scored as 0 (unable to do) to 4 (able to complete with no difficulty) and pain items as 0 (unbearable) to 4 (no pain). FADI has a total point value of 104

12 months

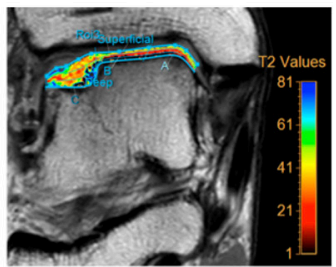

24 months

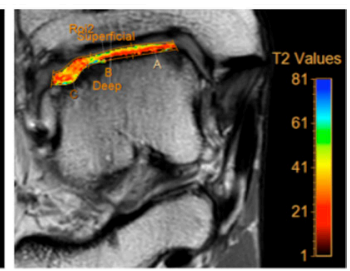

Figure 3 Sequential MRI T2 mapping of the area of cartilage regeneration over 24 months of follow-up. Values were compared against an area of native hyaline cartilage in the central talus. 
Table 1 Fluorescence-activated cell sorting surface marker analysis showing results consistent with mesenchymal stem cells as per the International Society of Cellular Therapy guidelines

\begin{tabular}{llllllll}
\hline \multicolumn{7}{c}{ Positive markers } & \multicolumn{5}{c}{ Negative markers } \\
\hline Percentage & CD90 +ve & CD73 +ve & CD105+ve & CD14 +ve & CD19+ve & CD34 +ve & CD45 +ve \\
& 98.44 & 99.87 & 99.12 & 0.74 & 0.09 & 0.91 & 0.8 \\
\hline
\end{tabular}

and is expressed as a percentage, with $100 \%$ indicating no dysfunction.

2. FADI Sport: The FADI Sport score consists of eight items similarly graded on a 5 -point Likert scale. ${ }^{31} 32$ FADI Sport has a total point value of 32 points and is also expressed as a percentage, with 100\% representing no dysfunction.

Questionnaires were completed remotely and online using the software programme Clinical Intelligence (Clinical Intelligence, Melbourne, Australia).

Structural outcome was assessed using repeat MRI performed at $0,3,8,12$ and 24 months. A modified International Cartilage Repair Society (ICRS) score (Grade 0 to 4 ) was used to describe the cartilage defect. ${ }^{33}$ Cartilage quality was assessed using the validated non-invasive MRI technique of T2-relaxation time cartilage mapping. ${ }^{345}$ Previous studies have used this technique to assess and quantify cartilage regeneration quality following interventions such as microfracture/drilling and also use of injectable bio-scaffolds such as BST-CarGel. ${ }^{11}$ Cartilage quality at the site of repair was assessed against native cartilage over a normal region in the mid portion of the talar dome-T2-relaxation time values in this region served as a comparative control.

\section{OUTCOME AND FOLLOW-UP \\ Functional outcome}

The patient showed progressive functional outcome during the follow-up period. Results at 12 months were not as good as seen at 6 months or 24 months and may reflect limitation of lower limb movement and function as a result of an acute knee injury at this time that was reported by the patient. FADI scores improved from $61 \%$ at baseline to $91 \%$ at 24 months indicating significant clinical improvement in function. While improvement was noted in FADI Sport, this still indicated considerable limitation. See figure 4.

\section{Structural outcome}

MRI imaging at 3 months post commencement of ADMSC showed incomplete cartilage-like tissue at the site of the OCL. A radiolucent line at the interface of cartilage-like tissue and subchondral plate suggested an unstable area of cartilage formation. Repeat MRI at 8 months showed continued maturation of cartilage like tissue though a persistent radiolucent line remained at the medial border of the new cartilage and subchondral plate. A 12-month MRI showed continued maturation of tissue with final MRI at 24 months showing robust hyaline-like cartilage infill/regeneration at the site of the previous OCL. The radiolucent area had resolved (see figure 2). Smooth integration with surrounding native cartilage was observed. Modified ICRS score improved from 3 at 3 months to 1 at 24 months.

\begin{tabular}{llll}
\hline $\begin{array}{l}\text { Table } 2 \\
\text { analyser }\end{array}$ & Cell count and viability as measured by the Muse cell \\
\hline \multicolumn{4}{l}{} \\
& Baseline injection & 6 month injection & 12 month injection \\
\hline ADMSC cell number & 21 million & 20 million & 52 million \\
Viability & $98.4 \%$ & $98.6 \%$ & $98 \%$ \\
\hline
\end{tabular}

ADMSC, adipose-derived mesenchymal stem cells.
Quantitative MRI T2 mapping analysis at 3 months indicated relaxation time values on average of $80 \mathrm{~ms}$ with best values recorded in superficial zones (average $54 \mathrm{~ms}$ ) and larger values recorded in the deep zone (average $110 \mathrm{~ms}$ ). Overall T2 relaxation time values improved throughout the period of follow-up, improving to an average of $65 \mathrm{~ms}$ at 24 months. T2 values at 24 months were comparable to values seen in native cartilage. See figure 3 and table 3 .

\section{Complications and adverse events}

No significant adverse events were noted throughout follow-up. The patient observed a self-limiting flare up in discomfort following each ADMSC injection. This lasted up to 1 week and required the use of ice and simple analgesics only. As the flares did not affect their daily activities, they were considered a mild adverse event.

\section{DISCUSSION}

This case study is the first documented use of ADMSC therapy in combination with arthroscopic excision and curettage of an OCL of the ankle. The patient had had prior unsuccessful ankle surgery and a most recent failure of a periosteal graft.

Throughout the follow-up period of 24 months, the patient reported marked functional improvement in daily activities and function as recorded by the FADI score. Despite seeing improvement in the FADI Sport score, these results were less significant and reflected persistent limitation in sporting pursuits and recreational activity. Treatment was well tolerated with no significant adverse events observed.

Repeat MRI analysis over the 24 months of follow-up showed progressive regeneration of cartilage over the site of the previous OCL. Final MRI at 24 months indicated almost complete fill of

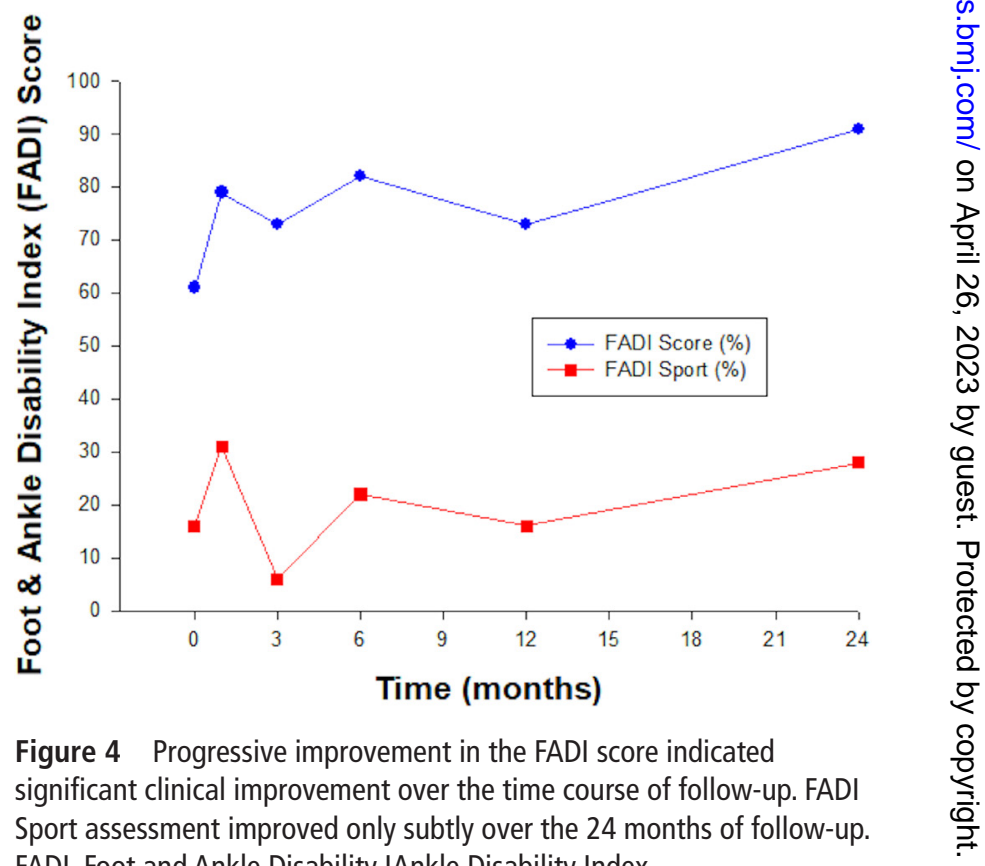
FADI, Foot and Ankle Disability IAnkle Disability Index. 
Table 3 MRI T2 relaxation time values in deep, intermediate and superficial zone of cartilage at the site of regrowth and also at a site of native cartilage. Native cartilage values were recorded over a normal region of cartilage in the mid portion of the talar dome and served as a control

\begin{tabular}{|c|c|c|c|c|}
\hline & \multicolumn{4}{|c|}{$\begin{array}{l}\text { MRI T2 relaxation times (mean milliseconds with average SD in } \\
\text { brackets) }\end{array}$} \\
\hline & 3 months & 12 months & 24 months & $\begin{array}{l}\text { Native cartilage at } 24 \\
\text { months (control) }\end{array}$ \\
\hline Deep zone & $110(120)$ & $100(110)$ & $80(40)$ & $70(20)$ \\
\hline Intermediate zone & $70(40)$ & $65(30)$ & $60(40)$ & $50(10)$ \\
\hline Superficial zone & $55(18)$ & $50(20)$ & $45(15)$ & $40(10)$ \\
\hline Overall & $80(80)$ & $75(60)$ & $65(30)$ & $55(15)$ \\
\hline
\end{tabular}

the defect with resolution of a previous area of lucency between the regenerative tissue and subchondral plate/calcified cartilage layer, which had been observed in previous MRIs. Progressive cartilage regeneration was reflected in a modified ICRS assessment improvement from 3 at 3 months to 1 at 24 months. T2 relaxation time values improved throughout follow-up with final values comparable to native cartilage, suggestive of hyaline-like cartilage morphology.

Marrow stimulation techniques such as microfracture/microdrilling have been associated with cartilage regeneration though past studies have shown predominantly Type I collagen on biopsy and significantly elevated T2 mapping values indicating fibrocartilage formation. ${ }^{36-39}$ Long-term efficacy of microfracture/ microdrilling in isolation is limited with past studies indicating progressive degeneration and recurrence of symptoms within 3 to 5 years. ${ }^{37}$ The observed progressive chondral regrowth and improved T2 mapping values over 24 months of follow-up is suggestive that ADMSC therapy in combination with curettage results in robust hyaline-like cartilage formation and may result in improved long-term outcome over bone marrow stimulation techniques in isolation. This is consistent with previous pre-clinical and clinical studies comparing microdrilling against microdrilling in combination with MSC therapy. ${ }^{224041}$

Observed improvement of T2 mapping values over 24 months indicated reduced water content and collagen anisotropy, suggestive of progressive maturing of cartilage. This is similar to what has been observed following ACI techniques whereby greater Type II collagen and hyaline-like properties are observed at 24 months versus 12 months of follow-up. ${ }^{42}$

Final T2 mapping values compared favourably against previously studied techniques. In a recent randomised controlled trial involving OCL of the ankle/talus, arthroscopic microfracture was compared against the use of BST-CarGel in combination with microfracture. ${ }^{39}$ Average T2 mapping values at 12 months were 85 and $70.5 \mathrm{~ms}$, respectively. Average native cartilage values were comparable to that of our patient $(51.5$ vs $55 \mathrm{~ms}$ respectively). Subsequent 5 -year outcome reporting of this randomised controlled trial has indicated progressive elevation of T2 values at the site of repair suggestive of degeneration. ${ }^{43}$ Whether the T2 values in this case study show on-going maturation and improvement or decline in longer-term follow-up is yet to be determined. Additional long-term follow-up to 5 years and beyond is intended. While arthroscopic biopsy would provide more definitive indication of Type II cartilage formation, repeat arthroscopy and possible morbidity associated with the biopsy site was not felt to be justifiable given the patient's functional and structural improvement.

In addition to the use of ADMSCs, ACS was used as a carrier media and may have had additional therapeutic benefit. Previous research has suggested that the combination of MSCs with blood derived growth factors may assist in the expression of collagen Type II and reduce chondrocyte apoptosis. ${ }^{44}$ Growth factors expressed in ACS including transforming growth factor beta1 (TGF $\beta 1$ ) and basic fibroblast growth factor (bFGF) have also been shown to assist in migration of MSCs to the site of injury. ${ }^{45}$ bFGF has also been shown to effectively suppress collagen type $\mathrm{X}$ formation and limit possible hypertrophic endochondral ossification which can result following bone marrow stimulation and graft techniques. ${ }^{46}$

Whether the observed cartilage regeneration was as a result of ADMSC integration into the site of repair and direct differentiation along a chondrocyte lineage is unknown. Past research has failed to reproducibly show integration of MSCs within articular cartilage repair and it is likely that the action of MSCs in regards to assistance in repair is achieved through cell to cell interaction and paracrine mechanisms. Additional use of cell labelling techniques such as magnetic tagging would allow for assessment of cell migration, integration and retention and would be beneficial in any future formal trials. ${ }^{47}$

Importantly, the results of this case report of an ankle OCL reflect the benefits observed in past trials assessing MSC therapy in combination with bone marrow stimulation techniques in the treatment of cartilage lesions of the knee. ${ }^{21-23}$ This suggests that this technique may have reproducible benefit in all focal cartilage lesions irrespective of the joint involved.

In this single case report, the treatment of an ankle talar OCL with autologous ADMSC therapy in combination with arthroscopic curettage resulted in successful functional and structural improvements. Treatment was well tolerated. This is the first observed use of this technique in the literature involving an OCL of the talar dome. The improved structural outcome against other well studied and currently used techniques suggests that that the novel use of ADMSC therapy is a promising treatment option. More wellstructured research is required to validate the observations of this

\section{Learning points}

- Ankle talar dome osteochondral lesions (OCLs) cause significant pain and morbidity with later development of osteoarthritis.

- Current conservative and surgical management of talus OCLs have inconsistent and limited success rates. Surgical techniques such as autologous chondrocyte implantation/ matrix-induced autologous chondrocyte implantation are additionally limited by complications including donor site morbidity and potential poor integration with surrounding native cartilage.

- The novel use of autologous adipose-derived mesenchymal stem cell (ADMSC) therapy in combination with arthroscopic curettage resulted in robust hyaline-like cartilage repair, smooth integration with native cartilage and concurrent functional improvement.

- In this case report, the use of autologous ADMSC therapy resulted in successful structural repair where previous surgical treatment intervention had failed.

- MSCs through both reparative and anti-inflammatory pathways represent an exciting therapeutic development in the treatment of joint pathology. The results of this novel case report with improvements observed against current treatment options highlight the importance of further validating wellstructured research. 
case report prior to ADMSC therapy being adopted as part of standard practice.

Acknowledgements The authors would like to acknowledge the following people for their contribution to the case study: Orthopaedic surgeon Mark Blackney for his role as the treating specialist foot and ankle surgeon. Radiologist Associate Professor David Connell and radiographer Mark Ward for assistance in MRI imaging and analysis. Ellee Picken, Melissa Grogan, Lesley-ann Kelly, Renee Castelluccio and Lucinda Kenihan for assistance in data acquisition

Contributors JF is a Sport and Exercise Medicine Physician and the treating physician of the patient presented in the case report. JF, JW, KS and AT were involved in the data acquisition, analysis of data and drafting of the report. JF, JW, KS and AT have read and approved the final manuscript. JF, JW, KS and AT agreed to be accountable for the article and to ensure that all questions regarding the integrity of the article are investigated and resolved.

Funding The authors have not declared a specific grant for this research from any funding agency in the public, commercial or not-for-profit sectors.

Competing interests JF is affiliated with Magellan Stem Cells and is a member of Magellan Stem Cells Clinical and Scientific Advisory Board. KS is affiliated with Magellan Stem Cells and is the Chief Scientific Officer of Magellan Stem Cells. AT is affiliated with Magellan Stem Cells and a member of Magellan Stem Cells Clinical and Scientific Advisory Board.

Patient consent for publication Obtained.

Provenance and peer review Not commissioned; externally peer reviewed.

Open access This is an open access article distributed in accordance with the Creative Commons Attribution Non Commercial (CC BY-NC 4.0) license, which permits others to distribute, remix, adapt, build upon this work non-commercially, and license their derivative works on different terms, provided the original work is properly cited and the use is non-commercial. See: http://creativecommons.org/ licenses/by-nc/4.0/.

\section{ORCID iD}

Julien Freitag http://orcid.org/0000-0001-6701-4368

\section{REFERENCES}

1 Berndt AL, Harty M. Transchondral fractures (osteochondritis dissecans) of the talus. Jone Joint Surg Am 1959;41-A:988-1020.

2 Prakash D, Learmonth D. Natural progression of osteo-chondral defect in the femoral condyle. Knee 2002:9:7-10.

3 Bhosale AM, Richardson JB. Articular cartilage: structure, injuries and review of management. Br Med Bull 2008;87:77-95.

4 Blom JM, Strijk SP. Lesions of the trochlea tali. osteochondral fractures and osteochondritis dissecans of the trochlea tali. Radiol Clin 1975:44:387-96.

5 Canale ST, Belding RH. Osteochondral lesions of the talus. J Bone Joint Surg Am 1980;62:97-102.

6 Huylebroek JF, Martens M, Simon JP. Transchondral talar dome fracture. Arch Orthop Trauma Surg 1985;104:238-41.

7 Pettine KA, Morrey BF. Osteochondral fractures of the talus. A long-term follow-up. J Bone Joint Surg Br 1987;69:89-92.

8 Zengerink M, Struijs PA, Tol JL, et al. Treatment of osteochondral lesions of the talus: a systematic review. knee surgery, sports Traumatology. Arthroscopy 2010;18:238-46.

9 Wohl G, Goplen G, Ford J, et al. Mechanical integrity of subchondral bone in osteochondral autografts and allografts. Can J Surg 1998;41:228-33.

10 Ahsan T, Lottman LM, Harwood F, et al. Integrative cartilage repair: inhibition by betaaminopropionitrile. J Orthop Res 1999;17:850-7.

11 Vilá Y Rico J, Dalmau A, Chaqués FJ, et al. Treatment of osteochondral lesions of the talus with bone marrow stimulation and Chitosan-Glycerol Phosphate/Blood implants (BST-CarGel). Arthrosc Tech 2015;4:e663-7.

12 Arinzeh TL. Mesenchymal stem cells for bone repair: preclinical studies and potential orthopedic applications. Foot Ankle Clin 2005;10:651-65

13 Barry FP, Murphy JM. Mesenchymal stem cells: clinical applications and biological characterization. Int I Biochem Cell Biol 2004;36:568-84.

14 Noël D, Djouad F, Jorgense C. Regenerative medicine through mesenchymal stem cells for bone and cartilage repair. Curr Opin Investig Drugs 2002;3:1000-4.

15 Caplan Al. Why are MSCs therapeutic? New data: new insight. J Pathol 2009;217:318-24

16 Peng L, Jia Z, Yin $\mathrm{X}$, et al. Comparative analysis of mesenchymal stem cells from bone marrow, cartilage, and adipose tissue. Stem Cells Dev 2008;17:761-74.

17 Alvarez-Viejo M, Menendez-Menendez Y, Blanco-Gelaz MA, et al. Quantifying mesenchymal stem cells in the mononuclear cell fraction of bone marrow samples obtained for cell therapy. Transplant Proc 2013;45:434-9.

18 Baer PC, Geiger H. Adipose-derived mesenchymal stromal/stem cells: tissue localization, characterization, and heterogeneity. Stem Cells Int 2012;2012:1-11.
19 Im G-I, Shin Y-W, Lee K-B. Do adipose tissue-derived mesenchymal stem cells have the same osteogenic and chondrogenic potential as bone marrow-derived cells? Osteoarthritis Cartilage 2005;13:845-53.

20 Peng L, Jia Z, Yin X, et al. Comparative analysis of mesenchymal stem cells from bone marrow, cartilage, and adipose tissue. Stem Cells Dev 2008;17:761-74.

21 Wakitani S, Goto T, Pineda SJ, et al. Mesenchymal cell-based repair of large, fullthickness defects of articular cartilage. J Bone Joint Surg Am 1994;76:579-92.

22 Saw K-Y, Anz A, Siew-Yoke Jee C, et al. Articular cartilage regeneration with autologous peripheral blood stem cells versus hyaluronic acid: a randomized controlled trial. Arthroscopy 2013;29:684-94.

23 Freitag J, Shah K, Wickham J, et al. The effect of autologous adipose derived mesenchymal stem cell therapy in the treatment of a large osteochondral defect of the knee following unsuccessful surgical intervention of osteochondritis dissecans - a case study. BMC Musculoskelet Disord 2017;18:298.

24 Freitag J, Li D, Wickham J, et al. Effect of autologous adipose-derived mesenchymal stem cell therapy in the treatment of a post-traumatic chondral defect of the knee. BMJ Case Rep 2017:79:bcr-2017-220852.

25 Freitag J, Bates D, Wickham J, et al. Adipose-derived mesenchymal stem cell therapy in the treatment of knee osteoarthritis: a randomized controlled trial. Regen Med 2019;14:213-30.

26 Freitag J, Ford J, Bates D, et al. Adipose derived mesenchymal stem cell therapy in the treatment of isolated knee chondral lesions: design of a randomised controlled pilot study comparing arthroscopic microfracture versus arthroscopic microfracture combined with postoperative mesenchymal stem cell injections. BMJ Open 2015;5:e009332

27 Zuk PA, Zhu M, Ashiian P, et al. Human adipose tissue is a source of multipotent stem cells. Mol Biol Cell 2002;13:4279-95.

28 Goh BC, Thirumala S, Kilroy G, et al. Cryopreservation characteristics of adiposederived stem cells: maintenance of differentiation potential and viability. J Tissue Eng Regen Med 2007;1:322-4.

29 Martinello T, Bronzini I, Maccatrozzo L, et al. Canine adipose-derived-mesenchymal stem cells do not lose stem features after a long-term cryopreservation. Res Vet Sci 2011:91:18-24.

30 Dominici M, Le Blanc K, Mueller I, et al. Minimal criteria for defining multipotent mesenchymal stromal cells. The International Society for cellular therapy position statement. Cytotherapy 2006;8:315-7.

31 Martin R, Burdett R, Irrgang J. Development of the foot and ankle disability index (FADI). J Orthop Sports Phys Ther 1999;29:A32-3.

32 Hale SA, Hertel J. Reliability and sensitivity of the foot and ankle disability index in subjects with chronic ankle instability. J Ath/ Train 2005;40:35.

33 Brittberg M, Winalski CS. Evaluation of cartilage injuries and repair. J Bone Joint Surg Am 2003;85-A(Suppl 2):58-69.

34 Crema MD, Roemer FW, Marra MD, et al. Articular cartilage in the knee: current MR imaging techniques and applications in clinical practice and research. Radiographics 2011:31:37-61.

35 Mamisch TC, Trattnig S, Quirbach S, et al. Quantitative T2 mapping of knee cartilage: differentiation of healthy control cartilage and cartilage repair tissue in the knee with unloading--initial results. Radiology 2010;254:818-26.

36 Jakobsen RB, Engebretsen L, Slauterbeck JR. An analysis of the quality of cartilage repair studies. J Bone Joint Surg Am 2005;87:2232-9.

37 Magnussen RA, Dunn WR, Carey JL, et al. Treatment of focal articular cartilage defects in the knee: a systematic review. Clin Orthop Relat Res 2008;466:952-62.

38 Mithoefer K, McAdams T, Williams RJ, et al. Clinical efficacy of the microfracture technique for articular cartilage repair in the knee: an evidence-based systematic analysis. Am J Sports Med 2009;37:2053-6.

39 Stanish WD, McCormack R, Forriol F, et al. Novel scaffold-based BST-CarGel treatment results in superior cartilage repair compared with microfracture in a randomized controlled trial. J Bone Joint Surg Am 2013;95:1640-50.

40 Saw K-Y, Hussin P, Loke S-C, et al. Articular cartilage regeneration with autologous marrow aspirate and hyaluronic acid: an experimental study in a goat model. Arthroscopy 2009;25:1391-400.

41 Mcllwraith CW, Frisbie DD, Rodkey WG, et al. Evaluation of intra-articular mesenchymal stem cells to augment healing of microfractured chondral defects. Arthroscopy 2011;27:1552-61

42 Vasiliadis HS, Wasiak J, Salanti G. Autologous chondrocyte implantation for the treatment of cartilage lesions of the knee: a systematic review of randomized studies. Knee Surg Sports Traumatol Arthrosc 2010;18:1645-55.

43 Shive MS, Stanish WD, McCormack R, et al. BST-CarGel 8 treatment maintains cartilage repair superiority over microfracture at 5 years in a multicenter randomized controlled trial. Cartilage 2015;6:62-72.

44 Mifune Y, Matsumoto T, Takayama K, et al. The effect of platelet-rich plasma on the regenerative therapy of muscle derived stem cells for articular cartilage repair. Osteoarthritis Cartilage 2013;21:175-85.

45 Zhu Y, Yuan M, Meng HY, et al. Basic science and clinical application of platelet-rich plasma for cartilage defects and osteoarthritis: a review. Osteoarthritis Cartilage 2013;21:1627-37. 
46 Weiss S, Hennig T, Bock R, et al. Impact of growth factors and PTHrP on early and late chondrogenic differentiation of human mesenchymal stem cells. J Cell Physiol 2010;223:84-93.
47 Budde MD, Frank JA. Magnetic tagging of therapeutic cells for MRI. J Nucl Med 2009;50:171-4.

Copyright 2020 BMJ Publishing Group. All rights reserved. For permission to reuse any of this content visit

https://www.bmj.com/company/products-services/rights-and-licensing/permissions/

BMJ Case Report Fellows may re-use this article for personal use and teaching without any further permission.

Become a Fellow of BMJ Case Reports today and you can:

- Submit as many cases as you like

- Enjoy fast sympathetic peer review and rapid publication of accepted articles

- Access all the published articles

Re-use any of the published material for personal use and teaching without further permission

Customer Service

If you have any further queries about your subscription, please contact our customer services team on +44 (0) 2071111105 or via email at support@bmj.com.

Visit casereports.bmj.com for more articles like this and to become a Fellow 